\title{
Children's basic memory processes, stress, and maltreatment
}

\author{
MARK L. HOWE, ${ }^{a}$ DANTE CICCHETTI ${ }^{b}$ AND SHEREE L. TOTH ${ }^{c}$ \\ ${ }^{a}$ Lancaster University; ${ }^{b}$ Institute of Child Development, University of Minnesota; and \\ ${ }^{c}$ Mt. Hope Family Center, University of Rochester
}

\begin{abstract}
Building upon methods and research utilized with normative populations, we examine extant assumptions regarding the effects of child maltreatment on memory. The effects of stress on basic memory processes is examined, and potential neurobiological changes relevant to memory development are examined. The impact of maltreatmentrelated sequelae (including dissociation and depression) on basic memory processes as well as false memories and suggestibility are also outlined. Although there is a clear need for additional research, the investigations that do exist reveal that maltreated children's basic memory processes are not reliably different from that of other, nonmaltreated children.
\end{abstract}

The field of developmental psychopathology has been characterized by a focus on the bidirectional relations between normal and atypical development (Cicchetti, 1984, 1993; Cicchetti \& Cohen, 2006; Rutter \& Sroufe, 2000; Sroufe, 1991; Sroufe \& Rutter, 1984). As such, the discipline of developmental psychopathology lends itself to providing a framework for the translation of normal developmental theory and research toward understanding developmental processes in atypical and disordered populations (Cicchetti \& Toth, 2006).

Given its emphasis on interdisciplinary collaborative efforts, the mutually enriching interplay between work with normal and atypical populations, and the examination of multiple domains of development (Cicchetti \& Cohen, 2006; Cicchetti \& Dawson, 2002; Cicchetti \& Sroufe, 2000; Institute of Medicine, 1989), a developmental psychopathology perspective serves as a powerful impetus for translating basic research on memory into the arena of

Preparation of this article was supported by a grant from the National Institute of Mental Health to the authors.

Address correspondence and reprint requests to: Mark L. Howe, Department of Psychology, Lancaster University, Lancaster, LA1 4YF, UK; E-mail: mark.howe@ lancaster.ac.uk. child maltreatment. In this article, we draw from the normative literature on memory in children to ascertain whether experiences of trauma differentially affect the operation of memory in maltreated children.

\section{Trauma and Memory}

Are traumatic experiences remembered better than nontraumatic experiences? Although most would agree that traumatic events are well etched in memory, there is considerable disagreement concerning their retrievability. On the one hand, there are those who suggest that although traumatic experiences are well encoded and stored, their retrievability into conscious awareness is inhibited by protective or defensive processes (e.g., Brewin \& Andrews, 1998; Herman, 1992). On the other hand, there is considerable evidence that traumatic events are not only well encoded and stored, but also are easily retrieved given the appropriate cues, much like other memories (e.g., Howe, Courage, \& Peterson, 1994). Indeed, traumatic experiences are often all too easily retrieved and involuntarily intrude into consciousness (e.g., Holmes, Grey, \& Young, 2005).

Most of the empirical evidence is consistent with this latter view. That is, traumatic 
events are not only encoded and stored quite well, but also are retained and retrieved remarkably better than some other events. Indeed, it is well documented that memories for trauma are generally very well retained, certainly better than memories for everyday, mundane events (e.g., Berntsen \& Thomsen, 2005). The reasons may be many and include possible neurobiological mechanisms such as emotional tagging of arousing events (RichterLevin \& Akirav, 2003), the enhanced role of the amygdala in the encoding, storage, and retrieval of emotionally arousing material (Adolphs, Denburg, \& Tranel, 2001; Adolphs, Tranel, \& Buchanan, 2005; Buchanan, Karafin, \& Adolphs, 2003), and changes in adrenergic and corticosteroid hormonal regulation (e.g., Abercrombie, Kalin, Thurow, Rosenkranz, \& Davidson, 2003; Domes, Rothfischer, Reichwald, \& Hautzinger, 2005; Maheu, Joober, Beaulieu, \& Lupien, 2004). In addition, there are any number of attentional and encoding variables that might lead to the enhancement of memory for trauma, particularly heightened sensitivity to environmental cues that signal risk, an attentional hypervigilance that makes an individual more alert to trauma-related cues in the environment (for a review, see Howe, Toth, \& Cicchetti, 2006).

However, the very processes that lead to better memory for traumatic events may lead to later alterations in basic memory processes. It has been speculated that to the extent stressors become a permanent fixture in a person's life (particularly a child's), what these changes could lead to are alterations in the way in which basic memory processes operate. For example, there is some evidence that early traumatic experiences can lead to alterations in hippocampal volume in some animals (specifically dendritic atrophy in the tree shrew; see Lucassen et al., 2001), although reports in humans are not as conclusive (for a review, see Howe et al., 2006). Moreover, stressinduced elevations in adrenal steroid levels have been linked to changes in neuronal connectivity in the hippocampus, ones that have behavioral correlates associated with memory (spatial and short term; McEwen, 1999). Although these changes may be transient, there is recent evidence suggesting persistent neuro- biological changes (e.g., decreased adult neurogenesis) that result from early stressful experiences (Karten, Olariu, \& Cameron, 2005; Kempermann, 2005; Lemaire, Koehl, Le Moal, \& Abrous, 2000).

However, does this mean that the basic memory processes that subserve the encoding, storage, retrieval, and retention of traumatic events are not subject to the same laws as those more mundane, everyday memories? As already noted, the empirical literature makes it abundantly clear that memories for traumatic events are better retained than those for more mundane events, particularly when those events are important (e.g., Berntsen \& Thomsen, 2005) or have significant personal consequences (e.g., Alexander et al., 2005). However, it is equally clear that traumatic memories are just as malleable (e.g., Nourkova, Bernstein, \& Loftus, 2004), reconstructive (Wessel \& Wright, 2004), susceptible to suggestion (Eisen \& Carlson, 1998), and forgotten with time (Wagenaar \& Groeneweg, 1990; Wessel \& Wright, 2004) as are more mundane events.

Although there is a considerable literature supporting these conclusions (for a review, see Howe et al., 2006), much of this work has been conducted with people who have experienced a single, acute traumatic episode (e.g., emergency room experience, tornado, war, death of a loved one). The question remains, do these conclusions hold for populations in which the trauma is ongoing and the stress chronic? Moreover, are such conclusions applicable to populations in which the neural substrates associated with memory are still developing? Specifically, do the neurobiological effects of chronic stress impact memory processes essential to remembering everyday and traumatic events, particularly in young children whose brains are still developing. That is, are basic memory processes (encoding, storage, retrieval, and retention) compromised by stress in maltreated children, and if so, does this lead to more impoverished memory traces, ones that are weaker, less resistant to interference, and more susceptible to suggestion. These questions are addressed in the remainder of this article where we examine the reliability of children's recollections for courtroom tes- 
timony and answer questions concerning the consequences of chronic stress on children's susceptibility to suggestion and false memories. We conclude with some speculation concerning the impact various therapeutic and legal interventions may have on the reliability of children's event memory over time.

\section{Child maltreatment and memory}

Neurobiological factors. What makes memory reliable? Once an event has been experienced, what is encoded and stored depends not only on the external stimulus situation but also on a person's expectations, knowledge, and processing capacity (for a review, see Howe, 2000). Whatever information is encoded can then be stored in memory for later retrieval. If the information being stored is of a traumatic nature, then in addition to the usual consolidation activity that leads to trace storage, other amygdala- and hormonally related inputs help the formation of a stable, wellintegrated memory trace (for a review, see Howe et al., 2006). Because of these additional inputs, traumatic experiences are not only stored quite well but also are retained remarkably well over long periods of time. Generally speaking, the better encoded and stored information is, the better integrated the trace structure, and the stronger, more durable the trace is over the long term (e.g., Howe, 2000).

Although most researchers would agree that traumatic events are stored quite well, they disagree on what happens to these traces during retention as well as what happens during attempts to retrieve information from these memories. At one extreme, there are those who would claim that once stored, traumatic memories become inaccessible to conscious recollection because they are repressed (e.g., Janet, 1907/1920; van der Kolk \& Fisler, 1995). Repression is a defense mechanism that prevents the person from becoming aware of the traumatic events and serves to protect them from the potentially negative consequences that reliving the trauma might cause, psychically. It is also speculated that although the memory is repressed, it remains accurate in all of its detail and is not subject to the usual forgetting forces (interference, decay, and so on) that befall other, consciously accessible memories.

These ideas stand in stark contrast to the empirical facts. As already noted, there is overwhelming evidence that the majority of traumatic experiences, including physical and sexual abuse in childhood, can be recalled (Alexander et al., 2005; Berntsen \& Thomsen, 2005; Cordon, Pipe, Sayfan, Melinder, \& Goodman, 2004; Howe et al., 2006). Moreover, traumatic memories are subject to the same forces over time as are nontraumatic memory traces. That is, they undergo forgetting (Wagenaar \& Groeneweg, 1990), are subject to interference from other memory traces (Howe, Courage, \& Peterson, 1995), and can be affected by misinformation (Eisen, Qin, Goodman, \& Davis, 2002). These findings suggest that repression, if it exists at all, does not prevent conscious recollection of traumatic experiences nor does it protect memories from being forgotten or altered in a manner similar to other memory traces. Given the overwhelming number of studies confirming the ease with which traumatic experiences can be recalled, it is no wonder that many have questioned whether repression occurs at all (see Loftus, 1994).

Given that traumatic memories are better stored than more mundane memories and that memories for traumatic experiences are reasonably easy to bring to mind voluntarily (as well as involuntarily; see Holmes et al., 2005), is there any evidence that the prolonged stress associated with chronic maltreatment in childhood should somehow perturb these basic "laws" of memory? To answer this question, consider the neurobiological consequences of child maltreatment. There is some evidence that myelinated areas of the developing brain are particularly susceptible to chronic stress (see De Bellis, 2005). However, adverse neural development has so far only been associated with maltreatment-related posttraumatic stress disorder (PTSD). For example, children with maltreatment-related PTSD, particularly males, have been shown to have a smaller corpus callosum (De Bellis et al., 1999; Teicher et al., 1997). There is also evidence for decreased cerebral volumes and attenuation of frontal lobe asymmetry in maltreated children with PTSD (Carrion et al., 2001). Finally, 
maltreatment-related PTSD is also associated with smaller cerebral and frontal cortices, less prefrontal white matter, and reduced right temporal lobe volumes (De Bellis et al., 2002). Clearly, then, child maltreatment that is associated with PTSD can and does have adverse consequences for neurological development, particularly in terms of age-appropriate myelination.

Of interest, none of these studies found adverse effects specific to neurological structures associated with memory. The smaller hippocampal volumes that have been reported for adults with child maltreatment-related PTSD (e.g., Bremner et al., 1997) has not been reported in the cross-sectional studies of pediatric PTSD just discussed nor have they been obtained in short-term longitudinal studies of pediatric maltreatment-related PTSD (e.g., De Bellis, Hall, Boring, Frustaci, \& Moritz, 2001). Indeed, there is the suggestion that hippocampal volumes might actually be larger in pediatric PTSD (De Bellis, 2005). One explanation for this discrepancy is that for maltreated children there is a higher risk for alcohol and substance abuse in adolescence and adulthood (De Bellis, 2002), behaviors that are related to decreased hippocampal volume (e.g., De Bellis et al., 2000). Alternatively, it may simply be that the adverse effects of chronic stress do not manifest themselves in the hippocampus until postpubertal development. Finally, these differences may be the result of neurogenesis in the hippocampus and frontal cortex (e.g., Gould \& Gross, 2002; Kempermann, 2005). Thus, neurodevelopmental plasticity and normal developmental increases in the hippocampus may "mask" any adverse effects of maltreatment. Thus, it does not appear that the chronic stress associated with maltreatment in childhood has any long-term deleterious effects on brain structures that are associated with memory. Although there do exist more global volumetric differences, it is not clear how or if these are related to memory. More importantly, these differences in neurobiological measures have not been linked to differences in children's memory performance.

Clinical considerations. What about differences in memory performance as a function of the psychological sequelae associated with child maltreatment? That is, do maltreated children perform more poorly than their nonmaltreated counterparts on memory tests as a function of psychopathologies or other sequelae that are a consequence of maltreatment? The quick answer is no. Indeed, maltreated children generally perform as well as other children on basic memory tasks, although this conclusion is based on relatively few studies.

To begin, consider memory studies of children who have maltreatment-related PTSD. Although considerable memory research has been conducted with adults diagnosed with PTSD, little research has been conducted with children. This is due in part to difficulties associated with PTSD diagnoses in children. Those studies that have been conducted have not produced a consistent set of findings. For example, children with PTSD performed more poorly than children without PTSD on a task that tapped long-term memory for everyday events (Moradi, Doost, Taghavi, Yule, \& Dalgleish, 1999). However, others have found no differences in memory performance between children with and without PTSD (e.g., Beers $\&$ De Bellis, 2002). Eisen et al. (2002) found that for maltreated children age 3 to 17 years, PTSD symptoms were associated with more errors of commission but also were associated with more correct recall. In general, then, those studies that have examined trauma- or maltreatment-related PTSD symptoms and children's long-term event memory have failed to find any consistent relationship between the PTSD and memory performance. Thus, it turns out that children's memory performance is unrelated to clinician's diagnoses of PTSD (also see Cordon et al., 2004).

Of interest, dissociation has been found to be related to better, not worse, memory in children. Dissociation is thought to occur during and immediately after a traumatic event, and serves either to reduce the amount of information encoded during the event or to isolate traumatic memories after the event, thereby preventing rehearsal but helping the individual cope. Unlike repression, dissociation does not cause these memories to become consciously unavailable, simply harder to access. 
Given their reduced accessibility, it is thought that at the very least dissociation should limit rehearsal leading to faster deterioration of trauma-related memory traces (Fivush \& Schwarzmueller, 1995). Dissociation is thought to be available early in infancy (Liotti, 1992) and in childhood, with younger children being more reliant on this mechanism to cope with stress than older children and adults (Lynn \& Rhue, 1994; Putnam, 1997).

What this suggests is that memory should be poorer in those children who evidence dissociation than in those who do not. As already noted, the evidence is quite the reverse. For example, children as young as 3 years of age who were the victims of maltreatment and scored high on measures of dissociation actually had more detailed memories of their abuse than did children who scored low on dissociation (Eisen et al., 2002). Thus, similar to the findings for PTSD, dissociation does not appear to have a deleterious effect on maltreated children's basic memory processes.

Finally, child maltreatment is a known risk factor for major depressive disorders (Heim $\&$ Nemeroff, 2001). Depression has been associated with overgeneral memory responses (i.e., producing generic scriptlike responses rather than specific memories) on autobiographical memory tests particularly with adults (e.g., Williams, 1996), although this result is not routinely observed (see Wessel, Merckelbach, \& Dekkers, 2002). In the only study conducted with children, more generic responses were produced by children whose experience of trauma (in this case, family violence) was accompanied by depression (Orbach, Lamb, Sternberg, Williams, \& DawudNoursi, 2001). However, as with PTSD and dissociation, these findings are not as simple and straightforward as one might like. There is considerable evidence that traumatized and depressed individuals can and do recall specific autobiographical episodes. In fact, recall of specific memories in these tasks routinely exceeds $50 \%$ and this number frequently climbs to over $75 \%$ (Dalgleish et al., 2003), suggesting that generic recall is the exception not the rule. Although a number of other problems exist in the literature relating depression and event recall (see Howe et al., 2006), it can be concluded that maltreatment-related depression, like maltreatment-related PTSD and dissociation, does not portend changes in children's basic memory processes.

False memories and suggestibility. Thus far, there are no reasons to believe that the chronic stress associated with child maltreatment has any detrimental impact on children's basic memory processes. Although considerably more research is needed, particularly longitudinal studies, the available evidence from neurobiological and clinical studies shows that maltreated children perform as well, and sometimes better, on many everyday memory tasks as do their nonmaltreated counterparts. In this section we consider potential differences in areas of memory functioning that have particular forensic relevance, namely false memories and susceptibility to suggestion and misinformation. Although maltreated children's basic memory functioning may be indistinguishable from other children's, perhaps maltreatment-related sequelae will have an impact on these children's susceptibility to misinformation generally, and the creation of false memories, specifically.

Once stored in memory, event information remains dynamic and can interact with new, incoming information (e.g., see Howe, 2000). More specifically, new and sometimes misleading information can interfere with previously stored traces, either creating false recollections or interfering with recall such that misinformation is produced rather than the original event. Young children are particularly susceptible to misinformation effects (although not necessarily to all forms of false memory; see later discussion in this section) and are highly susceptible to suggestion and misleading questions (Bruck \& Ceci, 1999; Ceci \& Friedman, 2000). This does not mean that children do not recall events correctly or that they will assent to all types of misinformation or misleading questions. For example, children tend not to be misled when the suggested actions are very different from those that were witnessed or experienced (see Pipe, Lamb, Orbach, \& Esplin, 2004). However, when misinformation refers to details experienced in a related context (e.g., Roberts \& 
Blades, 1998) or that are more plausible and congruent with the event (e.g., Lindberg, Keiffer, \& Thomas, 2000; Pezdek \& Hodge, 1999), children are more susceptible to suggestion.

There are a variety of explanations for the effects of misinformation, ranging from social compliance (Bruck \& Ceci, 1999) to source monitoring errors, something that prevents children (and sometimes adults) from correctly discriminating original event information from subsequently encoded, and potentially misleading, information (Roberts, 2002). It is also believed that misinformation effects are more likely when the strength of the original event information in memory is low (Holliday, Douglas, \& Hayes, 1999; Pezdek \& Hodge, 1999; but see Marche \& Howe, 1995) and when the content is self-generated or imagined rather than experienced (Foley \& Johnson, 1985). In forensic cases, some therapeutic techniques require children to imagine the context in which the criminal events occurred, use props to aid recall, or actually revisit the context in which the event occurred. Although these techniques can enhance recall under certain conditions, all of these techniques also enhance misinformation and suggestibility effects (for a review, see Salmon, 2001). Indeed, it is well known that many techniques that are routinely used to improve recollection also increase the likelihood of false memories (for reviews, see Everson \& Boat, 2002; Sternberg, Lamb, Esplin, Orbach, \& Hershkowitz, 2002).

Is there any reason to believe that children's memories for traumatic events should be any more or less susceptible to false recollection, misinformation, or suggestibility? If so, would this be any different for children whose trauma was ongoing and who were subject to maltreatment-related chronic stress? On the one hand, it could be hypothesized that memories for traumatic events, regardless of whether they are acute or ongoing, should be highly resistant to suggestion because they are better encoded and stored in memory than other events. (Of course, if one believes that dissociation limits encoding or reduces rehearsal limiting the strength of memory traces for traumatic events, then one would predict heightened suggestibility. However, because dissociation does not appear to have the predicted effects when examined empirically, such predictions about suggestibility also seem groundless.) On the other hand, because children are often reticent to discuss matters pertaining to abuse, the use of more intense interviewing techniques may produce higher rates of true and false recall. As well, depending on the interviewing technique being used and whether it is coupled with therapeutic intervention, by the time a child testifies about the abusive events, there is the distinct possibility that the child's recollection will have incorporated any misinformation that was generated during prior interviews. Moreover, maltreatment-related sequelae, although not related directly to recall as we have seen, may be important when considering a child's susceptibility to misinformation and false memories. That is, differences in dissociation, absorption, and psychopathology may contribute to variations in suggestibility rates (Eisen \& Carlson, 1998; Eisen \& Lynn, 2001). For example, dissociative children may exhibit less confidence in their memories, something that may translate into a greater vulnerability to misinformation. Such a pattern of increased susceptibility to suggestion (Eisen \& Lynn, 2001), implantation of false memories (Hyman \& Billings, 1998), and mistaking imagined events for real ones (Heaps \& Nash, 1999) has been obtained with adults who score high on tests of dissociation.

To anticipate the answer to this question with children, what little research there is on this topic shows that maltreated children are no more or less susceptible to misleading information (Eisen et al., 2002) or false memories (Howe, Cicchetti, Toth, \& Cerrito, 2004) than their nonmaltreated counterparts. This does not mean that maltreated children are not susceptible to suggestion or false memories, simply that they are no more vulnerable to these effects than are other children. Moreover, like other children (Bruck \& Melnyk, 2004; Chae \& Ceci, 2005), individual and age differences in maltreated children's susceptibility to misleading information exist.

To begin, consider some recent work on child maltreatment and suggestibility. Eisen et al. (2002) examined children (3-17 years 
old) who had been referred to an inpatient child abuse evaluation unit in a large hospital. There were three groups of children: those who were abused (physical abuse, sexual abuse, or both physical and sexual abuse), those who were neglected, and those who were neither abused nor neglected. Among the battery of tests, children were given an anogenital examination as well as a psychological consultation. At some point during the second and fifth days of the hospital experience (usually the day after the psychological consultation), children participated in a forensic interview. Using a semistructured interview procedure that minimized but did not eliminate leading questions, the interviewer also prompted recall using anatomical dolls, body charts, and other props to elicit as much information as possible about the maltreatment. On the fifth day, children were also interviewed about the anogenital examination they had undergone earlier in the week.

Overall, Eisen et al. (2002) found that age was the major predictor of children's memory performance, not abuse status. Indeed, maltreated children were no more likely to be confused by misleading questions than were nonmaltreated children. Moreover, individual differences in psychopathology, intelligence, or dissociation did not predict memory errors or suggestibility rates. It would seem that maltreated children are no different than other children when it comes to memory for traumatic experiences or their susceptibility to suggestion concerning stressful events.

Although maltreated children may not be more suggestible when it comes to memory for traumatic experiences, it is conceivable that there are differences in their false memory rates for neutral material. Howe et al. (2004) examined this question using the Deese-Roediger-McDermott (DRM) paradigm (Deese, 1959; Roediger \& McDermott, 1995). Here, children were exposed to lists of everyday words that converge on a single unpresented concept. For example, children might hear the words bed, rest, awake, tired, dream, wake, snooze, blanket, doze, slumber, snore, and nap. All of these words are associated with the unpresented critical lure sleep. When asked to recall this list of words, children (and adults) frequently include the unpresented lure sleep as part of their output stream. The rates of false recall using this paradigm can rival that of true recall for both children and adults. Moreover, false memories can be more durable than true memories, persisting over longer retention intervals for both children and adults (for a review, see Brainerd \& Reyna, 2005).

Unlike suggestibility effects, false memory illusions of this sort increase with age across childhood and into adulthood. This may be because of corresponding developmental changes in semantic memory (e.g., Brainerd \& Reyna, 2005 ), children's ability to process associative relations automatically (Howe, 2005), or both Regardless, like true recall, false memories increase with age in the DRM paradigm.

In the Howe et al. (2004) study, 60 middle socioeconomic status children, 51 nonmaltreated low socioeconomic status children, and 48 maltreated low socioeconomic status children were examined using the DRM procedure. Of the 48 maltreated children, $65 \%$ were emotionally maltreated, $83 \%$ were neglected, $31 \%$ were physically abused, and $17 \%$ were sexually abused. Consistent with the nature of maltreatment, the majority of maltreated children in this sample $(69 \%)$ had experienced multiple subtypes of maltreatment.

All of the children (ranging in age from 5 to 12 years old) were presented 12 different DRM lists using standard procedures and both recall and recognition measures. The results showed that, like suggestibility, false memory rates were related to age and not abuse status. For all groups of children, true and false memories increased with age but did not vary as a function of maltreatment. Although there were overall differences in recall rates as a function of socioeconomic status consistent with other findings in the literature on children's memory development, these differences were independent of maltreatment status.

Thus, despite reasons to believe that chronic stress associated with maltreatment might somehow alter children's susceptibility to suggestion and false memories, the results of two relatively large scale and independent studies suggest otherwise. Of course, many more studies are needed before we can conclude that there are no demonstrable effects of maltreatment on 
children's susceptibility to misinformation effects for neutral (Howe et al., 2004) or traumatic memories (Eisen et al., 2002). Indeed, there are some clear drawbacks to both of these studies that limit their generalizability. The materials used in the Howe et al. (2004) study in no way parallel the false memories alleged by some in forensic settings. Similarly, the interview techniques used by Eisen et al. (2002) were certainly less biased than those alleged to have been used in some clinical and forensic environments. These caveats aside, the research that does exist indicates that maltreated children are no poorer or better than other children at correct recall, false recall, or resisting misinformation. Instead, like the larger literature on children's memory development, the main factor controlling these differences in memory performance was age.

These findings possess important clinical and sociolegal implications. First, it is important to recognize that children who have been traumatized are no more likely to report inaccurately on their experiences than are nontraumatized children. Therapists need to accept children's recollections while carefully avoiding interpretations that might result in incorrect embellishment. It is particularly critical that lawyers and judges not view the testimony of traumatized children as somehow distorted as a function of the trauma, but rather recognize that these children's memories are likely to be as accurate as are recollections of age-matched nontraumatized children.

\section{Caveats, Conclusions, and Future Prospects}

What this overview has shown is that despite the chronic stress associated with child maltreatment, it is extremely difficult to provide evidence that children's basic memory processes are adversely affected. Although there is good reason to believe that basic memory processes should be affected by maltreatment, neurobiological, clinical, and basic memory studies have not been able to uncover any differences. Indeed, it did not matter whether we looked at encoding, storage, retention, or retrieval, maltreated children performed much like their nonmaltreated counterparts. Differences in dissociation, psychopathology, intelligence, and PTSD, among other factors, did not discriminate the memory performance of maltreated and nonmaltreated children.

Although repeated confirmation of the null hypothesis makes it difficult to draw strong conclusions, ones that go much beyond a reasonable doubt, the research reviewed here does leave us wondering where the memory differences might lie? Clearly, the studies conducted to date give us no reason to believe that a difference set of memory development "laws" pertain to those who have been abused and those who have not.

Having said this, of course, it is also clear that we need a considerably larger body of research before we can close the book on this matter. In particular, there is a need to conduct longitudinal studies where long-term changes in memory due to stress and maltreatmentrelated sequelae can be tracked within individuals. Moreover, we need a more comprehensive battery of memory tests, individual differences measures, and more precise subtyping of maltreatment. It may be that as we obtain these more microanalytic measures on more and more children across longer time frames, we will begin to see maltreatment-related differences in basic memory processes and their development. However, until that time, the studies reviewed here provide no rationale for the claim that basic memory processes or their development conform to a different set of rules for maltreated children than other, nonmaltreated children. The work reported herein also exemplifies the utility of drawing from a body of basic research with normative populations of children and exporting hypotheses and methods to populations of children experiencing adversity.

\section{References}

Abercrombie, H. C., Kalin, N. H., Thurow, M. E., Rosenkranz, M. A., \& Davidson, R. J. (2003). Cortisol variation in humans affects memory for emotionally laden and neutral information. Behavioral Neuroscience, 117, 505-516.

Adolphs, R., Denburg, N. L., \& Tranel, D. (2001). The 
amygdala's role in long-term declarative memory for gist and detail. Behavioral Neuroscience, 115, 983-992.

Adolphs, R., Tranel, D., \& Buchanan, T. W. (2005). Amygdala damage impairs emotional memory for gist but not for details of complex stimuli. Nature Neuroscience, 8, 512-518.

Alexander, K. W., Quas, J. A., Goodman, G. S., Ghetti, S., Edelstein, R. S., Redlich, A. D., et al. (2005). Traumatic impact predicts long-term memory for documented child sexual abuse. Psychological Science, $16,33-40$.

Beers, S. R., \& De Bellis, M. D. (2002). Outcomes of child abuse. Neurosurgical Clinics of North America, 13, 235-241.

Berntsen, D., \& Thomsen, D. K. (2005). Personal memories for remote historical events: Accuracy and clarity of flashbulb memories related to World War II. Journal of Experimental Psychology: General, 134, 242-257.

Brainerd, C. J., \& Reyna, V. F. (2005). The science of false memory. New York: Oxford University Press.

Bremner, J. D., Randall, P. Vermetten, E., Staib, L., Bronen, R. A., Mazure, C., et al. (1997). Magnetic resonance imaging-based measurement of hippocampal volume in posttraumatic stress disorder related to childhood physical and sexual abuse - A preliminary report. Biological Psychiatry, 41, 23-32.

Brewin, C. R., \& Andrews, B. (1998). Recovered memories of trauma: Phenomenology and cognitive mechanisms. Clinical Psychology Review, 18, 949-970.

Bruck, M., \& Ceci, S. J. (1999). The suggestibility of children's memory. Annual Review of Psychology, 50, 419-439.

Bruck, M., \& Melnyk, L. (2004). Individual differences in children's suggestibility: A review and synthesis. Applied Cognitive Psychology, 18, 947-996.

Buchanan, T. W., Karafin, M. S., \& Adolphs, R. (2003). Selective effects of triazolam on memory for emotional, relative to neutral, stimuli: Differential effects on gist versus detail. Behavioral Neuroscience, 117, 517-525.

Carrion, V. G., Weems, C. F., Eliez, S., Patwardhan, A., Brown, W., Ray, R. D., \& et al. (2001). Attenuation of frontal lobe asymmetry in pediatric posttraumatic stress disorder. Biological Psychiatry, 50, 943-951.

Ceci, S. J., \& Friedman, R. D. (2000). The suggestibility of children: Scientific research and legal implications. Cornell Law Review, 86, 34-108.

Chae, Y., \& Ceci, S. J. (2005). Individual differences in children's recall and suggestibility: The effect of intelligence, temperament, and self-perceptions. Applied Cognitive Psychology, 19, 383-407.

Cicchetti, D. (1984). The emergence of developmental psychopathology. Child Development, 55, 1-7.

Cicchetti, D. (1993). Developmental psychopathology: Reactions, reflections, projections. Developmental Re view, 13, 471-502.

Cicchetti, D., \& Cohen, D. (Eds.). (2006). Developmental psychopathology. New York: Wiley.

Cicchetti, D., \& Dawson, G. (Eds.). (2002). Multiple levels of analysis. Development and Psychopathology, 14, 417-666.

Cicchetti, D., \& Sroufe, A. (2000). The past as prologue to the future: The times, they've been a-changin' [Editorial]. Development and Psychopathology, 12, $255-264$.
Cicchetti, D., \& Toth, S. L. (2006). Developmental psychopathology and preventive intervention. In W. Damon (Ed.), Handbook of child psychology. New York: Wiley.

Cordon, I. M., Pipe, M.-E., Sayfan, L., Melinder, A., \& Goodman, G. S. (2004). Memory for traumatic experiences in early childhood. Developmental Review, $24,101-132$.

Dalgleish, T., Tchanturia, K., Serpell, L., Hems, S., Yiend, J., de Silva, P., et al. (2003). Self-reported parental abuse relates to autobiographical memory style in patients with eating disorders. Emotion, 3, 211-222.

De Bellis, M. D. (2002). Developmental traumatology: A contributory mechanism for alcohol and substance use disorders. Psychoneuroendocrinology, 27, 155-170.

De Bellis, M. D. (2005). The psychobiology of neglect. Child Maltreatment, 10, 150-172.

De Bellis, M. D., Clark, D. B., Beers, S. R., Soloff, P. H. Boring, A. M., Hall, J., et al. (2000). Hippocampal volume in adolescent-onset alcohol use disorders. American Journal of Psychiatry, 157, 737-744.

De Bellis, M. D., Hall, J., Boring, A.M., Frustaci, K., \& Moritz, G. (2001). A pilot longitudinal study of hippocampal volumes in pediatric maltreatment-related posttraumatic stress disorder. Biological Psychiatry, 50, 305-309.

De Bellis, M. D., Keshavan, M. S., Clark, D. B., Casey, B. J., Giedd, J. N., Boring, A. M., et al. (1999). Developmental traumatology part II: Brain development. Biological Psychiatry, 45, 1271-1284.

De Bellis, M. D., Keshavan, M. S., Shifflett, H., Iyengar, S., Beers, S. R., Hall, J., et al. (2002). Brain structures in pediatric maltreatment-related posttraumatic stress disorder: A sociodemographically matched study. Biological Psychiatry, 52, 1066-1078.

Deese, J. (1959). On the prediction of occurrence of certain verbal intrusions in free recall. Journal of Experimental Psychology, 58, 17-22.

Domes, G., Rothfischer, J., Reichwald, U., \& Hautzinger, M. (2005). Inverted-U function between salivary cortisol and retrieval of verbal memory after hydrocortisone treatment. Behavioral Neuroscience, 119 , 512-517.

Eisen, M. L., \& Carlson, E. B. (1998). Individual differences in suggestibility: Examining the influence of dissociation, absorption, and a history of child abuse. Applied Cognitive Psychology, 12, S47-S61.

Eisen, M. L., \& Lynn, S. J. (2001). Dissociation, memory, and suggestibility in adults and children. Applied Cognitive Psychology, 15, S49-S73.

Eisen, M. L., Qin, J., Goodman, G. S., \& Davis, S. L. (2002). Memory and suggestibility in maltreated children: Age, stress arousal, dissociation, and psychopathology. Journal of Experimental Child Psychology, $83,167-212$

Everson, M. D., \& Boat, B. W. (2002). The utility of anatomical dolls and drawings in child forensic interviews. In M. L. Eisen, J. A. Quas, \& G. S. Goodman (Eds.), Memory and suggestibility in the forensic interview (pp. 383-408). Mahwah, NJ: Erlbaum.

Fivush, R., \& Schwarzmueller, A. (1995). Say it once again: Effects of repeated questioning on children's event recall. Journal of Traumatic Stress, 8, 555-580.

Foley, M. A., \& Johnson, M. K. (1985). Confusions between memories for performed and imagined actions: A developmental comparison. Child Development, 56, $1145-1155$. 
Gould, E., \& Gross, C. G. (2002). Neurogenesis in adult mammals: Some progress and problems. Journal of Neuroscience, 22, 619-623.

Heaps, C., \& Nash, M. (1999). Individual differences in imagination inflation. Psychonomic Bulletin and Review, 2, 313-318.

Heim, C., \& Nemeroff, C. B. (2001). The role of childhood trauma in the neurobiology of mood and anxiety disorders: Preclinical and clinical studies. Biological Psychiatry, 49, 1023-1039.

Herman, J. L. (1992). Trauma and memory. New York: Basic Books.

Holliday, R. E., Douglas, K. M., \& Hayes, B. K. (1999). Children's eyewitness suggestibility: Memory trace strength revisited. Cognitive Development, 14, 443-462.

Holmes, E. A., Grey, N., \& Young, K. A. D. (2005). Intrusive images and "hotspots" of trauma memories in posttraumatic stress disorder: An exploratory investigation of emotions and cognitive themes. Journal of Behavior Therapy and Experimental Psychiatry, 36, 3-17.

Howe, M. L. (2000). The fate of early memories: Developmental science and the retention of childhood experiences. Washington, DC: American Psychological Association.

Howe, M. L. (2005). Children (but not adults) can inhibit false memories. Psychological Science, 16, 927-931.

Howe, M. L., Cicchetti, D., Toth, S. L., \& Cerrito, B. M. (2004). True and false memories in maltreated children. Child Development, 75, 1402-1417.

Howe, M. L., Courage, M. L., \& Peterson, C. (1994). How can I remember when "I" wasn't there: Longterm retention of traumatic memories and emergence of the cognitive self. Consciousness and Cognition, 3, 327-355.

Howe, M. L., Courage, M. L., \& Peterson, C. (1995). Intrusions in preschoolers' recall of traumatic childhood events. Psychonomic Bulletin and Review, 2, $130-134$.

Howe, M. L., Toth, S. L., \& Cicchetti, D. (2006). Memory and developmental psychopathology. In D. Cicchetti \& D. Cohen (Eds.), Developmental psychopathology: Developmental neuroscience (2nd ed., Vol. 2, pp. 629-655). New York: Wiley.

Hyman, I. E., \& Billings, F. J. (1998). Individual differences and the creation of false childhood memories. Memory, 6, 1-20.

Institute of Medicine. (1989). Research on children and adolescents with mental, behavioral, and developmental disorders. Washington, DC: Author.

Janet, P. (1907/1920). The major symptoms of hysteria. Oxford: Macmillan.

Karten, Y. J. G., Olariu, A., \& Cameron, H. A. (2005). Stress in early life inhibits neurogenesis in adulthood. Trends in Neurosciences, 28, 171-172.

Kempermann, G. (2005). Adult neurogenesis. Oxford: Oxford University Press

Lemaire, V., Koehl, M., Le Moal, M., \& Abrous, D. N. (2000). Prenatal stress produces learning deficits associated with an inhibition of neurogenesis in the hippocampus. Proceedings of the National Academy of Sciences of the United States of America, 97, 11032-11037.

Lindberg, M. A., Keiffer, J., \& Thomas, S. W. (2000). Eyewitness testimony for physical abuse as a function of personal experience, development, and focus of study. Journal of Applied Developmental Psychology, $21,555-591$.
Liotti, G. (1992). Disorganized/disoriented attachment in the etiology of the dissociative disorders. Dissociation: Progress in the Dissociative Disorders, 5, 196-204.

Loftus, E. F. (1994). The repressed memory controversy. American Psychologist, 49, 443-445.

Lucassen, P. J., Vollmann-Honsdorf, G. K., Gleisberg, M., Czeh, B., De Kloet, E. R., \& Fuchs, E. (2001). Chronic psychosocial stress differentially affects apoptosis in hippocampal subregions and cortex of the adult tree shrew. European Journal of Neuroscience, 14, 161-166.

Lynn, S. J., \& Rhue, J. W. (1994). Dissociation: Clinical and theoretical perspectives. New York: Guilford Press

Maheu, F. S., Joober, R., Beaulieu, S., \& Lupien, S. J. (2004). Differential effects of adrenergic and corticosteroid hormonal systems on human short- and longterm declarative memory for emotionally arousing material. Behavioral Neuroscience, 118, 420-428.

Marche, T. A., \& Howe, M. L. (1995). Preschoolers report misinformation despite accurate memory. Developmental Psychology, 31, 554-567.

McEwen, B. S. (1999). Stress and hippocampal plasticity. Annual Review of Neuroscience, 22, 105-122.

Moradi, A. R., Doost, H. T. N., Taghavi, M. R., Yule, W. \& Dalgleish, T. (1999). Everyday memory deficits in children and adolescents with PTSD: Performance on the Rivermead Behavioral Memory Test. Journal of Child Psychology and Psychiatry and Allied Disciplines, 40, 357-361.

Nourkova, V., Bernstein, D. M., \& Loftus, E. F. (2004). Altering traumatic memory. Cognition and Emotion, $18,575-585$.

Orbach, Y., Lamb, M. E., Sternberg, K. J., Williams, J. M. G., \& Dawud-Noursi, S. (2001). The effect of being a victim or witness of family violence on the retrieval of autobiographical memories. Child Abuse and Neglect, 25, 1427-1437.

Pezdek, K., \& Hodge, D. (1999). Planting false childhood memories in children: The role of event plausibility. Child Development, 70, 887-895.

Pipe, M.-E., Lamb, M. E., Orbach, Y., \& Esplin, P. W. (2004). Recent research on children's testimony about experienced and witnessed events. Developmental Review, 24, 440-468.

Putnam, F. W. (1997). Dissociation in children and adolescents: A developmental perspective. New York: Guilford Press.

Richter-Levin, G., \& Akirav, I. (2003). Emotionaltagging of memory formation-In the search for neural mechanisms. Brain Research Reviews, 43, 247-256.

Roberts, K. P. (2002). Children's ability to distinguish between memories from multiple sources: Implications for the quality and accuracy of eyewitness statements. Developmental Review, 22, 403-435.

Roberts, K. P., \& Blades, M. (1998). The effects of interacting in repeated events on children's eyewitness memory and source monitoring. Applied Cognitive Development, 12, 489-503.

Roediger, H. L., III, \& McDermott, K. B. (1995). Creating false memories: Remembering words not presented on lists. Journal of Experimental Psychology. Learning, Memory, and Cognition, 21, 803-814.

Rutter, M., \& Sroufe, L. A. (2000). Developmental psychopathology: Concepts and challenges. Development and Psychopathology, 12, 265-296.

Salmon, K. (2001). Remembering and reporting by children: The influence of cues and props. Clinical Psychology Review, 21, 267-300. 
Sroufe, L. A. (1991). Considering normal and abnormal together: The essence of developmental psychopathology. Development and Psychopathology, 2, 335-347.

Sroufe, L. A., \& Rutter, M. (1984). The domain of developmental psychopathology. Child Development, 55, $17-29$.

Sternberg, K. J., Lamb, M. E., Esplin, P. W., Orbach, Y., \& Hershkowitz, I. (2002). Using a structured interview protocol to improve the quality of investigative interviews. In M. L. Eisen, J. A. Quas, \& G. S. Goodman (Eds.), Memory and suggestibility in the forensic interview (pp. 409-436). Mahwah, NJ: Erlbaum.

Teicher, M. H., Ito, Y., Glod, C. A., Andersen, S. L., Dumont, N., \& Ackerman, E. (1997). Preliminary evidence for abnormal cortical development in physically and sexually abused children using EEG coherence and MRI. Annals of the New York Academy of Sciences, 821, 160-175.

van der Kolk, B., \& Fisler, R. (1995). Dissociation and the fragmentary nature of traumatic memories: Overview and exploratory study. Journal of Traumatic Stress, 8, 505-525.

Wagenaar, W. A., \& Groeneweg, J. (1990). The memory of concentration camp survivors. Applied Cognitive Psychology, 4, 77-87.

Wessel, I., Merckelbach, H., \& Dekkers, T. (2002). Autobiographical memory specificity, intrusive memory, and general memory skills in Dutch-Indonesian survivors of the World War II era. Journal of Traumatic Stress, 15, 227-234.

Wessel, I., \& Wright, D. B. (2004). Emotional memory failures: On forgetting and reconstructing emotional experiences. Cognition and Emotion, 18, 449-455.

Williams, J. M. G. (1996). Depression and the specificity of autobiographical memory. In D. C. Rubin (Ed.), Remembering our past: Studies in autobiographical memory (pp. 244-267). New York: Cambridge University Press. 